\section{THE FOURTH INTERNATIONAL CONFERENCE ON GENETICS.}

$\mathrm{THE}$ fourth International Conference on Genetics is the latest of a series of conferences which was inaugurated with the "Conference on Hybridisation" convened in 1899 by the Royal Horticultural Society. The Horticultural Society of New York undertook the organisation of the second conference, held in that city in 1902 ; the third "Conference on Plant-breeding" took place in London in 1906, again under the auspices of the Royal Horticultural Society; the fourth conference of the series, and the first to receive the title of "Conference on Genetics," has recently been held in Paris under the control of the Société Nationale d'Horticulture de France, which is to be very heartily congratulated on the success which attended all its arrangements.

As M. Ph. de Vilmorin has pointed out, genetics, though born of the studies provoked by the rediscovery of Mendelism, is itself of wider scope, and includes all that appertains to the physiology of heredity, the problems of fluctuating variation, selection, mutation, the transmission of acquired characters, cytology, \&c. Most of the subjects were represented among the communications brought before the recent conference. There were, indeed, no papers dealing purely with cytology, though Dr. Swingle brought forward the tentative suggestion that the diverse types encountered in certain $\mathrm{F}$, families might be due to different groupings within the cell of a given set of determinants; but the absence of cytological papers no more than reflects the present difficulty of producing any satisfactory cytological "explanation" of the phenomena of heredity, and we can only hope for better things in the future. Appended are short notes on a few of the communications made to the conference.

Messrs. Bateson and Punnett described some results of very great interest in regard to the special relations which have been found to exist in certain cases between distinct factors. Those who have followed recent progress in this work will remember that in not a few crosses, between plants differing from one another in respect of two characters, the phenomenon known as "partial coupling" between the factors for these characters has been exhibited; that is to say, the $F_{1}$ produces the four possible types of gamete, not in the approximately equal numbers which would result from a chance distribution of the factors, but in proportions represented by the general expression

$$
(n-\mathrm{I}) \mathrm{AB}: \mathrm{IA} b: \mathrm{r} a \mathrm{~B}:(n-\mathrm{I}) a b \text {, }
$$

where $n$ is any power of 2 and is equal to one-half the total number of gametes produced.

Other crosses, on the other hand, gave results which suggested that, in certain circumstances, the same two factors were repelled from one another in gametogenesis. Unlike the phenomena of coupling the repulsion appeared to be complete, so that no germ-cell received both factors, and consequently no germ-cell was without one of them.

This year, however, Punnett has discovered a case in which repulsion is not complete, but the gametes containing one or other of the two factors (but not both) are produced in greater numbers than the other types of gamete. That is to say, the middle terms of the gametic series are large, the end terms small-the converse to what occurs in "partial coupling "-and the gametic series is represented by the expression

$$
\mathrm{IAB}:(n-\mathrm{I}) \mathrm{A} b:(n-\mathrm{I}) a \mathrm{~B}: \mathrm{I} a b .
$$

In Punnett's case the gametic series was of the form $\mathrm{I}: 3: 3: \mathrm{x}$; even in this case, where $n$ has its lowest value, only one plant having both recessive characters is to be expected in every sixty-four $\mathrm{F}_{2}$ plants. With higher values of $n$, the proportion of double-recessives in $\mathrm{F}_{2}$ will be smaller still, and it can scarcely be doubted that this is the explanation of the cases hitherto regarded as representing complete repulsion; at the same time, the isolated occurrence of double-recessives in families exhibiting repulsion is explained.

The di-hybrid $F_{1}$ may therefore produce the four types of gametes in proportions ranging from

$$
\text { NO. } 2 \text { I90, VOL. 87] }
$$

through

to

$$
\begin{aligned}
& (n-1): \quad \text { I } \quad: \quad 1 \quad:(n-1)
\end{aligned}
$$

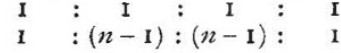

Bateson and Punnett point out that the conception underlying the terms "partial coupling" and "repulsion" is no longer justified, and they substitute the phrase "reduplication of terms" in a series of gametes.

Profs. Baür and Lotsy described experiments in crossing different species of snap-dragon. Antirrhinum majus (in the normal and peloric forms) was crossed reciprocally with $A$. molle, with $A$. latifolium, $A$. sempervivum, \&c. The characters of the hybrids and of the very numerous forms obtained in $\mathrm{F}_{2}$ were illustrated by means of coloured drawings. The experiments showed conclusively that segregation takes place in these species-crosses; how numerous are the factors to be considered may be judged from the fact that, of the $500 \mathrm{~F}_{2}$ plants raised, scarcely any two were alike. Among these plants there appeared an interesting new type resembling the flowers of the yellow-rattle (Rhinanthus) in the shape of the corolla.

Several papers dealing with cereals were presented, some of them of no little importance from the economic point of view. Dr. Nilsson-Ehle described experiments indicating that precocity and resistance to cold depend upon combinations of Mendelian factors. Dr. Surface described the results of selection for such characters as protein-content, \&c. He showed that in one case of successful selection for high protein-content, the plants raised after the ninth generation were all the descendants of a single progenitor, that is to say, selection had resulted in the isolation of a pure line possessing the desired quality. This result agrees with much that has been done since Johannsen first clearly presented the idea of pure lines, and agrees, too, with the new results which Prof. Boeuf communicated on the present occasion.

Dr. Orton described some work of the highest economic importance in the raising of varieties of agricultural plants resistant to the attacks of disease. Many varieties of cotton, the cow-pea (Vigna), and the water-melon are susceptible to the attacks of species of Fusarium; the cowpea, in addition, is liable to the attacks of the nematode Heterodora radicicola. Immune or highly resistant varieties of all these plants have now been obtained, in the case of the water-melon, however, only after crossing with a non-edible but resistant wild type.

At the session devoted to papers dealing with animals, Prof. Federley described an interesting case in Pygæra of the transmission of a disease through females, themselves unaffected by the disease, to their male offspring, all of which died of the disease. Dr. Walther, of Vienna, gave an account of his investigations into the inheritance of coat-colour in horses, a subject with regard to which he has secured a great wealth of material.

Finally, mention must be made of a new case of brachydactyly in man, described by Dr. Drinkwater. This case differs from the previous one in that there is no ankylosis of the short median phalange with the terminal phalange, and the fingers are intermediate in length between the extreme brachydactylous and the normal types. The abnormality is present in about one-half of the members of the affected family.

Much as there was of interest in the proceedings of the conference, not the least memorable of its features was the visit which the members were privileged to pay to the establishment of MM. Vilmorin, Andrieux et Cie. at Verrieres-le-Buisson. One's only regret was that the time at our disposal was all too short for even the most cursory inspection of the wonderful collection of plants which has been gathered together here, and of the experiments in breeding and selection which are being carried on by $\mathrm{M}$. Ph. de Vilmorin himself and by the firm of which he is the head. It is useless to attempt in a limited space to give any detailed description of Verrières; it need only be said that the whole establishment, gardens and museum alike, admirably reflects the enthusiasm which $\mathrm{M}$. $\mathrm{Ph}$ de Vilmorin, like the members of his family who have preceded him, has always shown for the scientific as well as the more obviously practical aspects of horticulture and plant-breeding. 